\title{
Lesões Bucais de Tecido Mole e Ósseo em Crianças e Adolescentes
}

\author{
ANA SUELI R. CAVALCANTE*, ANA LUCIA MARSILIO**, SANDRA S. KÜHNE***, YASMIM RODARTE \\ CARVALHO*
}

\section{RESUMO}

Neste estudo, os autores avaliaram a prevalência das lesões bucais de tecido mole e ósseo encontradas no complexo maxilomandibular, em crianças e adolescentes de zero a 14 anos. A amostra foi constituída de 370 pacientes, de ambos os sexos, atendidos na Faculdade de Odontologia de São José dos Campos. Dentre as sessenta lesões pesquisadas, a de maior freqüência foi o mucocele, totalizando 94 dos 370 casos encontrados $(25,40 \%)$, acometendo preferencialmente o sexo feminino, em idade entre 8 e 14 anos. Das dez lesões mais freqüentes relatadas neste estudo, nove necessitam de maiores conhecimentos sobre lesões bucais para fundamentar o diagnóstico clínico, indicando a importância da estomatologia.

\section{UNITERMOS}

Lesões bucais; mucosa bucal; ossos maxilo-mandibular; crianças; adolescentes; prevalência

CAVALCANTE, A.S.R., et al. Oral lesions found in children and adolescents. Pós-Grad. Rev. Fac. Odontol. São José dos Campos, v.2, n.1, p. 67-75, jan./jun., 1999.

\begin{abstract}
In this study the authors evaluated the prevalence of the oral lesions of soft and bony tissues found in the maxillomandibular apparatus in children and adolescents of zero to 14 years of age. The sample was constituted of 370 patient of both sexes, attended at Faculdade de Odontologia de São José dos Campos. Among the sixty researched lesions, the larger frequency accurred for mucus overfilling (mucocele), with 94 cases out of the 370 studied patient $(25,40 \%)$, occurring mainly in females with ages between 8 and 14 years. In this study, ten lesions had greater incidence, nine need larger knowledge on oral lesions to aid the clinical diagnosis, indicating the importance of the stomatological knowledge.
\end{abstract}

\section{UNITERMS}

Oral lesions; oral mucosa; maxillomandibulary bones; children; adolescents; prevalence.

* Departamento de Biopatologia e Diagnóstico - Faculdade de Odontologia de São José dos Campos - UNESP - 12245-000 São José dos Campos - SP.

** Aluna do Curso de Pós-Graduação em Odontologia - Área de Concentração em Odontologia Restauradora (Nível de Mestrado) / Faculdade de Odontologia de São José dos Campos - UNESP - 12245-000 - São José dos Campos - SP.

*** Estagiária da Disciplina de Semiologia (1993-1994) - Departamento de Biopatologia e Diagnóstico - Faculdade de Odontologia de São José dos Campos - UNESP - 12145-000 - São José dos Campos - SP 


\section{INTRODUÇÃO}

A literatura mundial apresenta um grande número de trabalhos referentes à cárie dental em crianças e doença periodontal em adultos, em razão disso, historicamente, o dentista tem sido associado com o tratamento do dente. As lesões de tecido mole e duro são uma realidade em termos de saúde bucal, entretanto, estudos sobre afecções de tecido mole e ósseos encontradas no complexo maxilomandibular não são relatados com tanta freqüência na literatura, bem como a prevalência dessas lesões orais e sua relação com sexo e idade ${ }^{1,9,16}$.

Entre os trabalhos disponíveis na literatura sobre as lesões bucais e do complexo maxilo-mandibular, verificamos que grande parte não aborda um estudo epidemiológico ${ }^{9}$, apenas citam quais as lesões que podem ser encontradas na faixa etária relacionada à infância e adolescência.

Segundo Luker \& Scully ${ }^{11}$ (1987) alguns distúrbios da mucosa oral, dentes, maxilares e glândulas salivares, que afetam os adultos, também podem afetar as crianças. Esses autores escreveram uma série de cinco artigos revisando as condições orais e periorais encontradas na infância e constataram que as lesões orais pré-malignas e malignas são raras em crianças, com exceção das manifestações orais da leucemia. Em seus estudos, foram comentadas as várias afecções que podem comprometer o paciente pediátrico, uma contribuição valiosa, mas sem estudo de prevalências. Referiram que as lesões brancas transitórias e persistentes, como candidíase pseudomembranosa aguda e líquen plano, são raras na infância e geralmente as lesões brancas persistentes são menos freqüentes que as transitórias. Relatam ainda, que as turgescências, são divididas em benignas, como mucoceles e hemangiomas, e turgescências malignas presentes em condições neoplásicas como nas leucemias ${ }^{12}$.

Grundy \& Shaw ${ }^{4}$ (1983) descreveram em uma série de quatro artigos sobre o estudo das lesões de tecido mole em crianças, relacionadas aos hábitos infantis e de lactentes, inflamações e infecções, tumores e cistos e condições diversas que acometem os tecidos moles orais. Esse estudo apenas relata quais as lesões que podem aparecer na cavidade oral, porém não faz referência à prevalência das mesmas. Dentre as lesões citadas por Grundy \& Shaw ${ }^{4-5,7}$
(1983) estão os cistos da lâmina dental dos recémnascidos, a gengivoestomatite herpética aguda, a candidíase, vulgarmente conhecida como "sapinho", os cistos de retenção de muco, neoplasias, ulcerações aftosas e injúrias não acidentais.

Alguns dos poucos estudos na literatura que fazem referência à prevalência das alterações e lesões da mucosa oral observaram, preferencialmente, crianças na faixa etária entre zero a $17 \operatorname{anos}{ }^{1,9}$, ${ }^{16}$. As lesões orais de tecido mole e ósseo do complexo maxilo-mandibular mais freqüentes, encontradas nas crianças em idade escolar, foram as ulcerações aftosas recorrentes, herpes labial, queilite angular, língua fissurada, lesões traumáticas e mucocele $^{1,9,16}$.

Keszler et al. ${ }^{8}$ (1990) em um estudo sobre patologia oral em crianças, verificaram a freqüência, distribuição e significado clínico das lesões. As alterações encontradas nas crianças representaram uma porcentagem de 6,8\% de todas as biópsias realizadas. Os diagnósticos histológicos obtidos foram divididos em: cistos, pseudotumores, lesões inflamatórias, neoplasias, lesões de cabeça e pescoço, anomalias dentárias e lesões pulpares e, ainda, diagnósticos não classificados, sendo que os cistos e lesões pseudotumorais foram as lesões orais mais freqüentes.

O paciente pediátrico pode apresentar lesões na mucosa oral como manifestações secundárias da leucemia ou terapia da mesma, outros cânceres, transplante de medula óssea e imunodeficiência adquirida e primária ${ }^{2,5,10,15,17}$. As leucemias e os linfomas são as neoplasias malignas que mais comprometem as crianças e são responsáveis pelo aparecimento de diferentes lesões na mucosa oral ${ }^{15}$. A imunossupressão causada pelas doenças oncológicas, imunodeficiência adquirida e primária pelo vírus HIV e por terapia imunossupressora, predispõe a criança à candidíase, que é a lesão mais comum em pacientes com deficiência imunológica, seguida por ulcerações aftosas recorrentes, doença periodontal, herpes simples e alterações nas glândulas salivares, principalmente em pacientes com Síndrome da Imunodeficiência Adquirida (AIDS) ${ }^{10}$.

Partindo-se do preceito de que há poucos dados na literatura sobre etiologia e prevalência das lesões orais de tecido mole e ósseo envolvendo o complexo maxilo-mandibular na infância, este tra- 
balho objetivou contribuir estudando a frequiência de lesões bucais nessa faixa etária correlacionando-as com o sexo e idade dos portadores.

\section{Material e Método}

Para a realização deste trabalho, levantamos a amostra através de uma ficha montada especialmente para esta pesquisa (Quadro 1) composta de pacientes assistidos nas Disciplinas de Semiologia e Patologia da Faculdade de Odontologia de São José dos Campos - UNESP. O grupo de estudo foi constituído por 370 pacientes, que, casualmente foram 185 do sexo masculino e 185 do sexo feminino, leucodermas e melanodermas, na faixa etária compreendida entre zero e 14 anos.

As lesões foram classificadas após exame clínico intra e extrabucal, anamnese, exame radiográfico, e biópsia para realização de exame anátomo-patológico do material removido, para complementação do diagnóstico final.

Após a determinação do diagnóstico, os diferentes tipos de lesões encontradas foram correlacionadas com sexo e faixa etária. Consideramos crianças e adolescentes entre zero e 14 anos, sendo divididos em grupos de zero a sete anos e de oito a 14 anos. Os exames anátomo-patológicos das lesões biopsiadas foram considerados mandatórios na determinação do diagnóstico, entretanto, a ficha clínica elaborada para este estudo foi de suma importância para o levantamento do diagnóstico diferencial e obtenção do diagnóstico final. A ficha clínica utilizada para todos os pacientes está descrita no Quadro 1.

\section{Resultados}

Os resultados obtidos após a avaliação das 370 crianças e adolescentes revelaram sessenta diferentes tipos de afecções que estão apresentados na Tabela 1.

As dez lesões de maior prevalência em ordem decrescente foram: mucocele, processo inflamatório crônico inespecífico, cisto dentígero, granuloma periodontal apical, granuloma piogênico, sialoadenite crônica, papiloma, hiperplasia papilomatosa irritativa, lesão periférica de células gigantes e cisto não-odontogênico. O mucocele foi a afecção mais expressiva, com 94 dos 370 casos avaliados, perfazendo um total de $25,40 \%$. Essa lesão teve maior frequiência no sexo feminino e na faixa etária entre oito e 14 anos.

Das sessenta lesões diagnosticadas, podemos notar que houve uma ocorrência maior nas crianças e adolescentes que tinham entre oito e 14 anos. A lesão de maior frequiência apresentou $25,40 \%$ das amostras e a segunda mais freqüente, $9,45 \%$. Três tipos de lesões ficaram acima de 5\%, duas acima de $4 \%$, uma acima de $3 \%$, quatro acima de $2 \%$, sete acima de $1 \%$ e quarenta e uma lesões obtiveram frequiência inferior a $1 \%$. Em razão disso discutiremos o trabalho enfatizando as dez afecções mais freqüentes.

\section{Discussão}

Os resultados demonstram que houve uma grande variedade de afecções encontradas no grupo de pacientes avaliados quando comparados aos demais estudos disponíveis na literatura. Entretanto, segundo Silva \& Marcucci ${ }^{16}$ (1990), devemos considerar alguns fatores que podem interferir com os resultados, tais como:

a) procedência dos serviços em que foram realizados. Geralmente são serviços especializados, tornando a amostra viciada, pois aqueles que procuram estes serviços fatalmente apresentam algum tipo de alteração;

b) origem das amostras, pois estas variam de acordo com sua localização geográfica, sujeitas a variações ecológicas, climáticas, mudanças de hábitos e costumes;

c) época em que foram realizados os trabalhos, metodologia e nomenclatura utilizada;

d) a falta de uniformidade dos critérios adotados

O mucocele, também denominado histologicamente por Grundy \& Shaw ${ }^{6}$ e Luker \& Scully ${ }^{11}$ de cisto de extravasamento de muco, é uma lesão decorrente de traumas ou obstrução dos ductos das glândulas salivares acessórias, podendo ou não ter revestimento epitelial. Yamasoba et al. ${ }^{18}$ referem que histologicamente há dois tipos de mucoceles: 
cisto de extravasamento de muco e cisto de retenção de muco. Regesi \& Sciuba ${ }^{14}$ confirmam ser o mucocele empregado apenas no cenário clínico, como um termo genérico, antes do diagnóstico microscópico. Neville et al. ${ }^{13}$ apresentam, de forma menos confusa, as definições clínicas e microscópicas do mucocele, inclusive referindo que muitos autores incluem o cisto de retenção de muco na série de mucoceles reportados na literatura. Quando essas lesões situam-se no assoalho da boca, são denominadas clínicamente de rânula, em sua maioria originárias das glândulas salivares maiores, freqüentemente a glândula sublingual. $\mathrm{O}$ fenômeno de extravasamento (mucocele ou rânula) se diferencia do cisto de retenção de muco, por apresentar um revestimento de epitélio do ducto ${ }^{14}$.

Quadro 1 - Ficha clínica

\begin{tabular}{|c|c|}
\hline \multicolumn{2}{|c|}{ FICHA CLÍNICA } \\
\hline \multicolumn{2}{|l|}{ ANAMNESE } \\
\hline \multicolumn{2}{|l|}{ Nome: } \\
\hline Endereço: & Tel.: \\
\hline Cidade: & UF.: \\
\hline Sexo: & Data Nascimento: \\
\hline \multicolumn{2}{|l|}{ Raça: } \\
\hline Naturalidade: & Nacionalidade: \\
\hline \multicolumn{2}{|l|}{ Procedência: } \\
\hline \multicolumn{2}{|l|}{ Queixa Principal: } \\
\hline \multicolumn{2}{|l|}{ História da Doença Atual: } \\
\hline \multicolumn{2}{|l|}{ História Médica: } \\
\hline \multicolumn{2}{|l|}{ Tratamento Médico Atual: } \\
\hline \multicolumn{2}{|l|}{ Antecedentes Familiares: } \\
\hline \multicolumn{2}{|l|}{ EXAME FÍSICO } \\
\hline \multicolumn{2}{|l|}{ Exame Extra-Bucal: } \\
\hline \multicolumn{2}{|l|}{ Exame Intra-Bucal: } \\
\hline \multicolumn{2}{|l|}{ Observações Gerais: } \\
\hline \multicolumn{2}{|l|}{ Hábitos: } \\
\hline \multicolumn{2}{|l|}{ Diagnóstico Diferencial: } \\
\hline \multicolumn{2}{|l|}{ Exames Complementares: } \\
\hline Diagnóstico Final: & \\
\hline
\end{tabular}


Tabela 1 - Prevalência das lesões orais quanto ao sexo e faixa etária expressas em números absolutos e relativos (continua)

\begin{tabular}{|c|c|c|c|c|c|c|c|}
\hline & $\begin{array}{c}\text { LESÕES } \\
\text { ORAIS }\end{array}$ & $\begin{array}{l}\text { casos } \\
(\text { abs. })\end{array}$ & $\begin{array}{c}\text { casos } \\
\text { (rel.) }\end{array}$ & masc. & fem. & $\begin{array}{c}\text { idade } \\
0-7\end{array}$ & $\begin{array}{l}\text { idade } \\
8-14\end{array}$ \\
\hline 1 & Mucocele & 94 & $25,40 \%$ & 30 & 54 & 14 & 80 \\
\hline 2 & Processo Inflamatório Crônico & 35 & $9,45 \%$ & 18 & 17 & 5 & 30 \\
\hline 3 & Cisto Dentígero & 21 & $5,67 \%$ & 12 & 9 & 8 & 13 \\
\hline 4 & Granuloma Periodontal Apical & 20 & $5,40 \%$ & 10 & 10 & 0 & 20 \\
\hline 5 & Granuloma Piogênico & 20 & $5,40 \%$ & 10 & 10 & 3 & 17 \\
\hline 6 & Sialoadenite Crônica & 17 & $4,59 \%$ & 8 & 9 & 4 & 13 \\
\hline 7 & Papiloma & 16 & $4,32 \%$ & 7 & 9 & 7 & 9 \\
\hline 8 & Hiperpl. Papilomatosa Irritativ & 12 & $3,24 \%$ & 7 & 5 & 5 & 7 \\
\hline 9 & Lesão Periférica Céls. Gigantes & 11 & $2,97 \%$ & 11 & 0 & 8 & 3 \\
\hline 10 & Cisto Não-Odontogênico & 10 & $2,70 \%$ & 6 & 4 & 1 & 9 \\
\hline 11 & Fibroma Ossificante Periférico & 9 & $2,43 \%$ & 5 & 4 & 0 & 9 \\
\hline 12 & Hiperpl. Gengival Inflamatória & 8 & $2,16 \%$ & 6 & 2 & 0 & 8 \\
\hline 13 & Hemangioma & 7 & $1,89 \%$ & 3 & 4 & 0 & 7 \\
\hline 14 & Processo Inflamatório Agudo & 7 & $1,89 \%$ & 4 & 3 & 2 & 5 \\
\hline 15 & Fibroma & 7 & $1,89 \%$ & 4 & 3 & 2 & 5 \\
\hline 16 & Osteomielite de Garré & 6 & $1,62 \%$ & 4 & 2 & 0 & 6 \\
\hline 17 & Odontoma & 5 & $1,35 \%$ & 3 & 2 & 0 & 5 \\
\hline 18 & Linfangioma & 4 & $1,08 \%$ & 3 & 1 & 1 & 3 \\
\hline 19 & Fibrobratoma & 4 & $1,08 \%$ & 1 & 3 & 1 & 3 \\
\hline 20 & Displasia Ectodérmica & 3 & $0,81 \%$ & 3 & 0 & 0 & 3 \\
\hline 21 & Gemgivite Crônica & 3 & $0,81 \%$ & 1 & 2 & 0 & 3 \\
\hline 22 & Lesão Central de Céls. Gigantes & 3 & $0,81 \%$ & 2 & 1 & 0 & 3 \\
\hline 23 & Verruga Vulgar & 3 & $0,81 \%$ & 1 & 2 & 2 & 1 \\
\hline 24 & Cisto Lâmina Dent. Rec.-Nasc. & 2 & $0,54 \%$ & 1 & 1 & 2 & 0 \\
\hline 25 & Dentes Natais & 2 & $0,54 \%$ & 1 & 1 & 2 & 0 \\
\hline 26 & Fibromatose Gengival Irritativa & 2 & $0,54 \%$ & 0 & 2 & 1 & 1 \\
\hline 27 & Hiperpl. Fibrosa Inflamatória & 2 & $0,54 \%$ & 1 & 1 & 0 & 2 \\
\hline 28 & Linfoma & 2 & $0,54 \%$ & 1 & 1 & 1 & 1 \\
\hline 29 & Mucosite Crônica & 2 & $0,54 \%$ & 2 & 0 & 2 & 0 \\
\hline 30 & Neurofibroma & 2 & $0,54 \%$ & 2 & 0 & 0 & 2 \\
\hline 31 & Querubismo & 2 & $0,54 \%$ & 2 & 0 & 0 & 2 \\
\hline 32 & Acrodermatite Enteropática & 1 & $0,27 \%$ & 0 & 1 & 1 & 0 \\
\hline 33 & Afta & 1 & $0,27 \%$ & 1 & 0 & 1 & 0 \\
\hline 34 & Cicatriz Fibrosa & 1 & $0,27 \%$ & 0 & 1 & 0 & 1 \\
\hline 35 & Displasia Epitelial Grave & 1 & $0,27 \%$ & 0 & 1 & 0 & 1 \\
\hline 36 & Fragmento Ósseo Esclerótico & 1 & $0,27 \%$ & 1 & 0 & 0 & 1 \\
\hline 37 & Herpes Simples & 1 & $0,27 \%$ & 0 & 1 & 1 & 0 \\
\hline 38 & Leucoplasia & 1 & $0,27 \%$ & 0 & 1 & 0 & 1 \\
\hline 39 & Língua Despapilada & 1 & $0,27 \%$ & 1 & 0 & 0 & 1 \\
\hline 40 & Lipoma & 1 & $0,27 \%$ & 1 & 0 & 0 & 1 \\
\hline
\end{tabular}


Tabela 1 - Prevalência das lesões orais quanto ao sexo e faixa etária expressas em números absolutos e relativos (conclusão)

\begin{tabular}{llcccccc}
\hline \multicolumn{1}{c}{$\begin{array}{c}\text { LESÕES } \\
\text { ORAIS }\end{array}$} & $\begin{array}{c}\text { casos } \\
\text { (abs.) }\end{array}$ & $\begin{array}{c}\text { casos } \\
\text { (rel.) }\end{array}$ & masc. & fem. & $\begin{array}{c}\text { idade } \\
0-7\end{array}$ & $\begin{array}{c}\text { idade } \\
8-14\end{array}$ \\
\hline 41 & Melanose Fisiológica & 1 & $0,27 \%$ & 1 & 0 & 0 & 1 \\
\hline 42 & Mésio-Dens & 1 & $0,27 \%$ & 1 & 0 & 0 & 1 \\
\hline 43 & Neuroma de Amputação & 1 & $0,27 \%$ & 1 & 0 & 1 & 0 \\
\hline 44 & Neurofibromatose Múltipla & 1 & $0,27 \%$ & 0 & 1 & 0 & 1 \\
\hline 45 & Osteoblastoma & 1 & $0,27 \%$ & 0 & 1 & 1 & 0 \\
\hline 46 & Osteomielite & 1 & $0,27 \%$ & 0 & 1 & 1 & 0 \\
\hline 47 & Displasia Fibrosa Monostótica & 1 & $0,27 \%$ & 1 & 0 & 0 & 1 \\
\hline 48 & Adenoma Pleomórfico & 1 & $0,27 \%$ & 1 & 0 & 1 & 0 \\
\hline 49 & Candidíase & 1 & $0,27 \%$ & 0 & 1 & 0 & 1 \\
\hline 50 & Hiperqueratose & 1 & $0,27 \%$ & 1 & 0 & 0 & 1 \\
\hline 51 & Pulpite Crônica & 1 & $0,27 \%$ & 1 & 0 & 0 & 1 \\
\hline 52 & Queratocisto & 1 & $0,27 \%$ & 0 & 1 & 0 & 1 \\
\hline 53 & Grânulos de Fordyce & 1 & $0,27 \%$ & 1 & 0 & 0 & 1 \\
\hline 54 & Abscesso Dento-Alveolar & 1 & $0,27 \%$ & 1 & 0 & 1 & 0 \\
\hline 55 & Sequestro Ósseo & 1 & $0,27 \%$ & 1 & 0 & 0 & 1 \\
\hline 56 & Sialolitíase & 1 & $0,27 \%$ & 1 & 0 & 1 & 0 \\
\hline 57 & Tatuagem de Amálgama & 1 & $0,27 \%$ & 0 & 1 & 0 & 1 \\
\hline 58 & Actinomicose & 1 & $0,27 \%$ & 1 & 0 & 0 & 1 \\
\hline 59 & Nevus Juncional & 1 & $0,27 \%$ & 1 & 0 & 0 & 1 \\
\hline 60 & Neoplasia de Céls. Fusiformes & $100 \%$ & 185 & 185 & 81 & 289 \\
\hline & TOTAL & & & & & 1 &
\end{tabular}

Clinicamente, a mucosa da superfície da lesão apresenta-se esticada, dando uma cor azulada pelo acúmulo de muco na cavidade formada na lâmina própria. Esta lesão pode apresentar-se superficial ou mais profundamente, sua coloração pode estar esbranquiçada por trauma contínuo com formação de queratina, a consistência freqüentemente é mole podendo também ser borrachosa quando fibrosada por trauma. Podem surgir em qualquer região da mucosa bucal, mas ocorrem preferencialmente na face interna do lábio inferior (Figuras 1-3).

Neste estudo pudemos observar que o mucocele foi a lesão de tecido mole mais freqüente entre as sessenta afecções diagnosticadas. Dentre as 370 biópsias realizadas, verificamos 94 casos de mucocele, perfazendo $25,40 \%$ do total da amostra. O sexo feminino foi o mais atingido com 54 casos contra trinta no sexo masculino e quanto à faixa etária esta diferença foi ainda maior, com oitenta casos entre oito e 14 anos contra 14 casos em crianças de zero a sete anos.

O trabalho de Keszler et al. ${ }^{8}$ foi o que mais se aproximou por ser uma amostra de zero a 15 anos, ter resultados equivalentes em ambos os sexos e ter como lesão de tecido mole mais freqüente o mucocele. Crivelli et al. ${ }^{1}$ e Kleinman et al. ${ }^{9}$, em seus estudos sobre a prevalência das lesões da mucosa oral em crianças e adolescentes em uma faixa etária variável de quatro a 17 anos, também tiveram o mucocele como uma lesão presente mas não a mais freqüente.

Yamasoba et al. ${ }^{18}$ realizaram um estudo clínico-estatístico de mucocele no lábio inferior em setenta pacientes, 32 do sexo masculino e 38 do sexo feminino em uma faixa etária de dois até 63 anos. A maior incidência ocorreu na segunda década de 


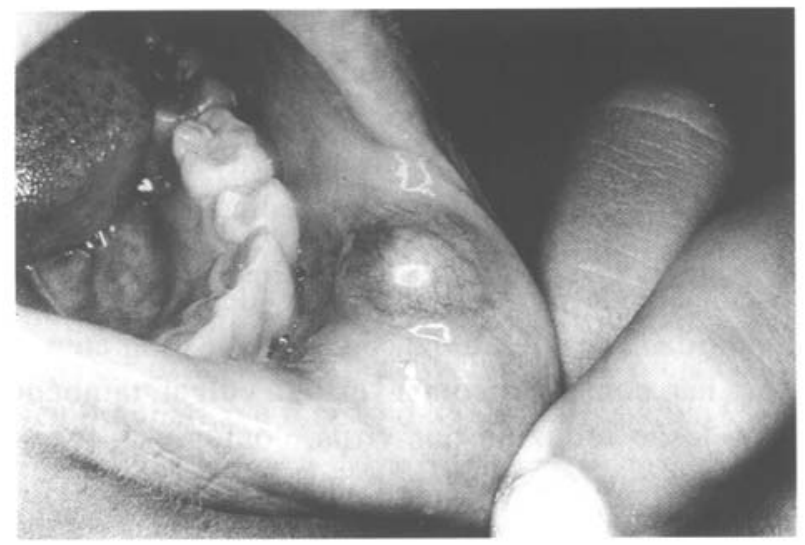

FIG URA 1 - M ucocele-turgescência no lábio inferior. A specto clínico de um a lesão superficial, séssil.

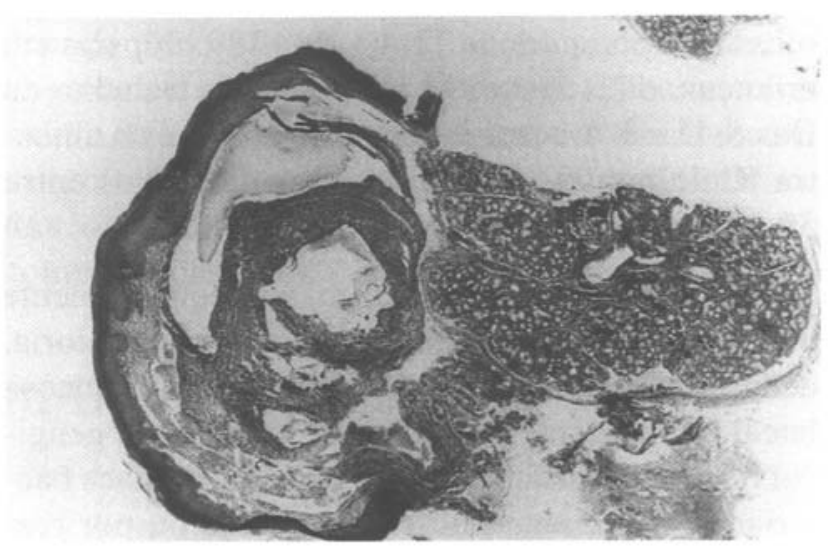

vida, ou seja, 70\% das lesões acom eteram pacientes com menos de vinte anos, o que está próxim o da nossa projeção que foi acentuadamente maior na fáxa etária de oilo a 14 anos em relação a de zero a sete anos.

0 processo inflam atóric crônico inespecífico foi a segunda lesão m ais freqüente, apresentando 9,45 \% dos casos. A freqüência entre os sexos foi equivalente, pois dos 35 casos, 18 oconeram no sexo m asculino e 17 no sexo fem inino, porém, quanto à idade, houve uma variação bem maior, porque enquanto ocomeram trinta casos na faixa etária entre oito e 14 anos, observam os som ente cinco casos na faixa de zero a sete anos. $\mathrm{Na}$ nossa revisão da literatura, não encontramos nada com essa classificação histológica. Clinicam ente podem os ter em sua m aioria um a lesão de tecido m ole, de aspecto uncerado ou atrófico ou esbranquiçado ou um a m istura dessas lesões com diagnóstico clínico indefinido. No tecido ósseo também a lesão se apresenta de form a indefinida clínica e radi

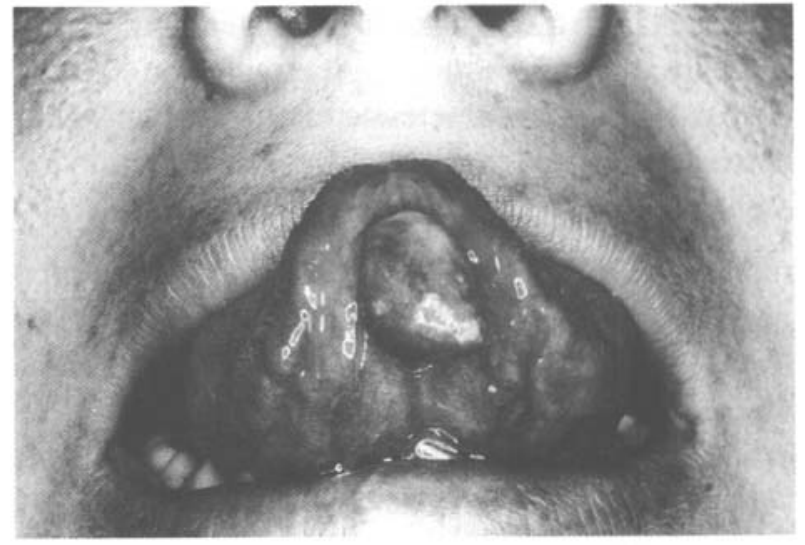

FIG URA 2 -M ucocele- lesão nodular. superficiale pediculada, no ventre da língua.
FIG URA 3 -M ucocele-histológico 25x.C avidade abaixo da m ucosa de
revestim ento contendo m ucina e células inflam atónias (esquerda) e ácinos
salivares (direita).

graficam ente. A penas $O$ trabalho de $K$ leinm an et al. ${ }^{9}$ refere-se a úlcera não específica no caso de lesões de tecido m ole.

0 cisto dentúgero foi m ais um a lesão encontrada com freqüência em nosso estudo. E definida como um cisto que se origina pela separação do folícu que contoma a coroa de um dente não errpcionado. Este é o tipo de cisto odontogênico de desenvolvimento mais comum, cerca de $20 \%$ de todos os cistos de cápsula epitelial dos maxilares. Pode envolver qualquer dente, mas $m$ ais freqüentem ente $\bigcirc$ terceito molar mandibular, descoberto nos pacientes entre dez e trinta anos de idade. Radiograficam ente, o cisto dentígero típico, mostra uma área radiolícida unibaular que está associada com a coroa de um dente não errpcionado ${ }^{13}$. Para Keszler et al ${ }^{8}$ (1990) o cisto dentígero foi quantitativam ente importante, representando 27,7\% dos casos em 1289 biópsias estudadas, ficando após os cistos radiculares $(60,4 \%)$ e antes dos queratocistos $(4,8)$. Em nosso estudb, os cistos dentígeros 
representaram $5,67 \%$ de 340 pacientes, sendo a terceira lesão $m$ ais freqüentes dentre os tecidos moles e ósseos, comprom etendo mais o sexo m asculino na faixa etária de oito a 14 anos.

Dentre as dez lesões $m$ ais freqüentes neste estudo, a única que pode ser resolvida pelo clínico geral ou endodontista, sem a necessidade do auxíli especializado do estom atologista, é o granuloma periodontal apical, representando 5,40\% dos casos, com oconência equivalente entre os sexos e som ente na fáxa etária de oito a 14 anos.

0 granuroma piogênico é um processo proliferativo não neoplásico que ocone com freqüência na gengìa, mas pode surgir ocasionalm ente em outras regiões da mucosa bucal e pele. A credita-se que resulte de traum a e/ou infecção que estimulam a form ação de um exuberante tecido altam ente vascularizado ${ }^{13}$. Em estudos prévios, o granuloma piogênico foi inchúdo no grupo das hiperplasias inflam atórias e lesões pseudotum orais ${ }^{8}$. 0 tíico granulom a piogênico é uma lesão verm elha, ocasionalm ente pode iscar ulcerado em conseqüência de traum atismo secundário ${ }^{14}$. Pode exibir crescim ento rápido o que pode assustar o paciente e o clínico. É uma lesão que pode se desenvolver em qualquer idade, mas é mais comum em criança e actulto jovem ${ }^{13}$. Neste trabalho encontram os vinte casos de granuloma piogênico, com distribuição equivalente entre homens e mulheres e total incidência na faixa etária dos oito aos 14 anos.

A siabadenite crônica é um achado histopatológico que estar presente em sua maioria com o m ucocele. Pode ser deconente do traum a que o paciente produz quando da presença do m ucocele, m ordendo repetidas vezes a lesão pelo incôm odo de algo estranho no local afetado. O bservam os 17 casos de siabadenite crônica, comespondendo a 4,59\% do total, sendo oilo casos no sexo m asculino e nove no sexo fem inino, 13 deles na fáxa etária de oito a 14 anos e oto casos entre zero a sete anos.

O utra lesão encontrada com relativa freqüência neste estudo foi o papilom a, presente em 4,32\% da am ostra. D os 16 casos, sete estavam presentes no sexo masaulino e nove no sexo fem inino com a mesma distribuição oconendo na faixa etária. 0 papiloma é uma proliferação benigna do epitéli escam oso estratificado, presum ivem ente induzido pelo papilom avírus hum a no (HPV). É mais com um ente diagnosticado em pacientes de trinta a cinqüenta anos de idade, com a mesma freqüência em homens e mulheres. E uma lesão exofilica, mole, com num erosas projeções na sua supenfície, usuamente pediculada e assintom ático. Pode ser branca, suavem ente verm elha ou da cor da mucosa adjacente, dependendo da quantidade de queratinização. Deve-se estar atento para não confundir com a venuga vulgar, tam bém uma lesão incuzida por vírus, contagiosa, incom um na mucosa bucal, e mais encontrada em crianças. A pele das m ãos usualm ente é o sitio de infecção ${ }^{13-14}$. No trabalho de Keszler et al ${ }^{8}$ (1990) o papilom a aparece com o a lesão m ais freqüente do giupo das neoplasias benignas não-odontogênicas com preendendo $11,4 \%$ de 1289 biópsias em crianças, e $2,1 \%$ de 2370 biópsias do trabalho de $\mathrm{D}$ as \& $\mathrm{D}$ as ${ }^{3}$. A veruga vulgar só aparece na am ostra $\mathrm{K}$ leinm an et al. ${ }^{9}$ com apenas dez casos entre 39206 crianças exam inadas.

As lesões hiperplásicas $m$ ais freqüentem ente diagnosticadas na infância, s̃̃o, em sua maioria, deconentes de trauma na língua, lábio e mucosa bucal por acidente, seguido por hiperplasia gengiva] reacional/inflam atória à presença de placa bacteriana por higiene bucal inadequada ou por reação a algum tipo de medicam ento e/bu doença sistêm ica. Das \& Das ${ }^{3}$, em sua pesquisa, levantaram hiperplasia fibrosa Inflamatória/reativa e Keszlér et al ${ }^{8}$ a hiperplasia inflamatóra gengiva] e a hiperplasia fibrosa gengival, bem com o Grundy \& Shaw ${ }^{7}$ que referem a hiperplasia gengiva] como uma lesão freqüente na infância. Como nosso trabalho não pesquisou a localização e algum as am ostras foram coletadas diretam ente de laudos histopatológicos, com poucos dados clínicos, não podem os elucidar m elhor o porque dessa freqüência e da nom enclatura, nessa faixa etária.

A lesão periférica de células gigantes é um a lesão relativamente comum, pode se desenvolver em qualquer idade, mas mostra ser mais prevalente na quinta e sexta década. Provavem ente não representa um a verdaderia neoplasia mas uma lesão reacional causada por initação local ou trauma. O cone exchusivamente na gengiva ou rebordo alveolar desolentado, apresenta-se com o um a massa nootular vermelha ou azul averm elhada. Apesar de se desenvolver no tecido mole, algum as vezes é visto reabsorção do osso adjacente. Pode ser séssil 
ou pediculada e pode estar ulcerada ou não. A aparêncía clínica é sim ilarao granulom a piogênico ${ }^{13}$.

Os cistos não odontogenicos m ais com uns na faixa etária estudada encontrados na literatura são, o cisto epiderm oide, o cisto ósseo traum ático e outros ${ }^{3-8}$. N osso trabalho refere apenas com o cistos não odontogênicos e nesta classificação podem os ter os cistos de desenvolvim ento, o cisto ósseo traum ático e o cisto ósseo aneurism átioo ${ }^{13}$.

Q uando nos referm os as lesões bucais, devem os considerar todas as afecções da mucosa bucal e ossos do complexo $m$ axio -m andibular. Para isso o dentista deve estar ciente das várias situaçães as quais pode estar a prova. Quando diante de um a doença grave nossa contribuição pode ser m uito im portante no diagnóstico precoce e acompanham ento do paciente. As m anifestações das leucem ias, um a doença que com prom tete 30 a

$40 \%$ de todas as neoplasias malignas na infância. As com plicações orais associadas à terapia do câncer.

\section{REFERÊNC IAS B BBLIO GRÁFICAS}

CRIVELLI, M R. et al Influence of socioeconomico status on mucosa lesion prevalence in schoolchildren. Community Dent. O ral Epidem ibl, v16, n. 1.p. $58-60, \mathrm{Feb} .1988$.

DAHLLOF, G. et al Oral health in children treated $w$ ith bone manow transplantation: a one-year follow-up. J. Dent. Child., v. 55, n. 3, p. 196-200,M ay//une 1988.

DAS, S., DAS, A. K. A review of pediatric oral biopsies from a surgical pathology service in a dentalschool. PediatrD ent., v.15, n. 3, p. 208-11, 1993.

GRUNDY, M., SHAW, L. Soft tissue lesions in children: 1. Infancy, teething and childhood habits. Dent. U pdate, v. 10, n. 5, p. 329-39, June 1983.

GRUNDY, M., SHAW, L. Soft tissue lesions in chiddren: 2. Inflammation and infection. Dent.U pdate, v.10,n. 6, p. 377-81, July 1983.

GRUNDY, M ; SHAW, L. Soft tissue lesions in children: 3. Tumours and cysts. Dent. Update v. 10, n.8, p. 495-501, Sept1983.

GRUNDY, M.: SHAW, L. Soft tissue lesions in childhen: 4. M iscellaneous conditions. Dent. U pdate, v.10, n.9, p.585-590, Oct. 1983.

KESZLER, A. GUGLELMOTTI, M B. DOM ÍNGUEZ, F.V. Oral pathology in children. Frequence, distribution and clinical significance. Acta Odontol. Latinoamer.,v.5, n.1, p. 39-48,1990.

KLEINMAN， D.V. SW ANGO，PA. PINDBORG，JJ. Epidem iblogy of oral m ucosal lesions in United States schoolchiblren: 1986
A imunodeficiência primária ou adquirida. A candidíase, uma das lesões m ais com uns em pacientes com doenças debilitantes, e outras com o herpes simples, mucosites, ulcerações, infecções bacterianas, gengiviles, xerostom ia, cárie, sangram ento gengival e da m ucosa oral e hiperplasias ${ }^{9-12-14}$

A pesar da nossa am ostra ser de pacientes encam inhados por presença de lesão ou de m aterial de biópsia, podem os dem onstrar a variedade de lesões que podem ser encontradas na mucosa bucal e ossos do complexo maxito -m andibular. Isso constata a necessidade em aprim orar os conhecim entos de dentistas clínicos gerais, odontopediatras e médicos pediatras na área da estomatologia. Este trabalho utilizou uma amostra pequena e Imitada em ralação as inúmeras afecções que podem comprom eter a criança e o adulto jovem. Novos trabalhos se fazem necessários bem com o maior conscientização, tanto dos dentistas com o da com unidade, para a im portância à atenção da saúde bucal

87.Com m unity D ent. O ralEpidem iol-v 22,n.4,p.243-53,Aug. 1994

LEGGOTT, PJ. et ai. Oral manifestations of primary and acquired im m unodeficiency diseases ni children. Pediat. Dent, v. 9, n. 2, p. 98-104, 1987.

LUKER, J. SCULLY , C. Paediatric oral medicine: 1. Soft tissue lesions of the face and N eck.Dent.Update, v. 14, p. 391-99, Nov.1987.

LUKER, J., SCULLY, C. Paediatric oral medicine: 5. The oral mucosa (ii). Dent Update, v. 15, n. 9, p.370-3,Nov.1988.

NEVILLE, B. W . et al. Oral \& maxillofacial pathobgy. Philadelphia: W . B . Saunders, 1995.p. 322-6, 371-4.

REGESI, J. A., SCUUBBA，J. J. Patobgia bucal: comelaç̃es clinico-patológicas. $R$ io de Janeiro: G uanabara Koogan, 1991 p 162-7.

SCULLY, C. MacFARLANE, TW. Orofacial manifestations of chibhood malignancy: clinical and $m$ icrobiblogical findings during rem ission. J. Dent.Child..v. 50.n.2,p.121 5,M ar./Apr.1983.

SILVA , SS., M ARCUCCI, G. Contribuição para o estudo clínico da prevalência das alterações da mucosa bucal em escolares de 7 a 12 anos. Rev. Odontol USP, v.4,n.1.p.1-4, Jan.M ar. 1990 .

SIMON, AR., ROBERTS, M W . M anagement of oral complications associated with cancer therapy in ediatric patients. J. Dent. Child., v. 58, n. 5. p. 384-9, Sep. 0 ct. 1991.

yAm ASOBA, T. et ai. Clinicostatistical study of lower lip mucoceles. Head \& Neck,v.12,n.4,p.316-20, July/Aug. 1990. 